\title{
Adenomegalias «intermitentes»: um caso clínico em medicina geral e familiar
}

Andreia Priscila Abreu Silva Araújo Caldeira,* Raquel dos Santos Parreira,* Paula Alexandra de Figueiredo Peixoto Marques Atalaia*

\section{RESUMO}

Introdução: As adenomegalias são achados frequentes do exame objetivo, sendo importante o médico de família identificar aquelas com grau de suspeição e referenciar atempadamente. Este caso mostra uma manifestação imprevisível de adenomegalias de características suspeitas, que aparecem e regridem espontaneamente ao longo de anos. Com este relato de caso pretende-se chamar à atenção para a necessidade de valorizar sempre as adenomegalias suspeitas, bem como elucidar acerca da abordagem diagnóstica destas manifestações.

Descrição do caso: Mulher de 69 anos, com antecedentes de tuberculose ganglionar em 2008, tratada com tuberculostáticos durante nove meses. Em 2014, na sequência de novas adenomegalias cervicais e supraclaviculares à direita, de características suspeitas, foi iniciada investigação, que foi inconclusiva dada a regressão espontânea do quadro. Dois anos depois recorre à consulta com adenomegalias supraclaviculares à esquerda, motivando nova investigação, nomeadamente com citologia aspirativa do gânglio, que mostrou a presença de células neoplásicas. Foi encaminhada para cirurgia geral para biópsia excisional do gânglio, cujo diagnóstico foi linfoma não-Hodgkin folicular. Iniciou quimioterapia no IPO com boa tolerância e resposta.

Comentário: O linfoma folicular é indolente, podendo apresentar-se com adenomegalias que aparecem e regridem espontaneamente durante anos, pelo que esta característica imprevisível dificulta o diagnóstico. No entanto, a continuidade de cuidados, característica da medicina geral e familiar, é facilitadora da atuação do médico de família, permitindo-nos detetar a recorrência do quadro e encaminhar atempadamente.

Palavras-chave: Linfadenopatia; Linfoma não-Hodgkin folicular

\section{INTRODUÇÃO}

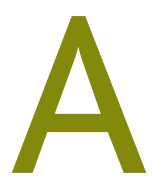

s adenomegalias são achados frequentes do exame objetivo e as etiologias são variadas. Na presença de um doente com adenomegalias importa fazer uma história clínica detalhada, verificar a sua localização, as características e o envolvimento de outros órgãos, de forma a chegar ao diagnóstico. As causas podem ser situações benignas, como infeções comuns ou adenomegalias reativas, inespecíficas e transitórias, ou situações graves como as doenças linfoproliferativas, infeções sistémicas, metástases ou outras. Os estudos mostram que apenas 1\% das linfadenopatias nos cuidados de saúde primários

USF do Parque, ACeS Lisboa Norte são de etiologia maligna. ${ }^{1}$ Alguns sinais de alarme podem estar presentes, nomeadamente as dimensões da adenomegalia $\geq 1,5 \mathrm{~cm} \mathrm{x} \geq 1,5 \mathrm{~cm}$ ou $\geq 2 \mathrm{~cm}$ de maior eixo. ${ }^{1}$ A consistência dura ou firme e indolor pode apontar para malignidade (metástase ou linfoma), embora outras doenças malignas, como a leucemia aguda, se possam apresentar com adenomegalias de consistência mole e dolorosas pelo seu crescimento rápido. ${ }^{1-2} \mathrm{~A}$ presença de sintomas B (febre, suores e perda de peso) deve alertar-nos para a presença de linfoma ou tuberculose ganglionar, embora os linfomas indolentes não apresentem esta sintomatologia. ${ }^{2}$ É importante o médico de família identificar precocemente uma causa comprometedora da vida do doente e referenciá-la atempadamente. 
Este artigo retrata um caso de uma utente com adenomegalias suspeitas que se manifestam com regressão espontânea e reaparecimento ao longo de anos. Pretende-se chamar a atenção para a necessidade de valorizar sempre as adenomegalias suspeitas, bem como elucidar acerca da abordagem diagnóstica destas manifestações.

\section{DESCRIÇÃO DO CASO}

Este caso refere-se a uma mulher de 69 anos, raça caucasiana, de nacionalidade portuguesa e residente em Alvalade. É casada e tem dois filhos. Atualmente reside com o marido, o filho e a sua mãe, fazendo parte de uma família alargada. Encontra-se reformada, tendo sido contabilista. Toca cavaquinho como hobby.

Como antecedentes pessoais tem a destacar uma perturbação depressiva reativa à situação de toxicodependência do filho. Não tem antecedentes cirúrgicos nem internamentos e não possui hábitos tabágicos, alcoólicos ou toxifílicos. Encontrava-se medicada com sertralina 100mg por dia e fazia suplementos de aloé vera. Apresenta o plano nacional de vacinação atualizado. Não viajou recentemente para o estrangeiro e não tem animais de estimação.

Como antecedentes familiares relevantes tinha um irmão gémeo que faleceu aos 46 anos com uma neoplasia na medula óssea, que não sabe especificar.

Em novembro de 2008, a utente recorreu à consulta por uma tumefação na base do pescoço à direita. Não apresentava febre, suores, perda de peso, cansaço ou outra sintomatologia da região da cabeça e pescoço ou da região torácica e negava contactos com casos de tuberculose. À observação apresentava adenomegalias cervicais e supraclaviculares à direita, de consistência dura, contornos regulares, aderentes aos planos profundos, com $2 \mathrm{~cm}$ x $2 \mathrm{~cm}$. Não existiam outras adenomegalias e a observação da cabeça, pescoço, tórax e abdómen não revelou alterações adicionais. Tinha uma mamografia recente que estava normal. Foram colocadas as hipóteses diagnósticas de tuberculose ganglionar, doença linfoproliferativa ou metástases da região da cabeça, pescoço, pulmão, mama ou gastrointestinal. Foi pedida ecografia do pescoço, raio X (Rx) do tórax, análises, citologia aspirativa do gânglio e prova de Mantoux.
A ecografia do pescoço mostrou a presença de uma massa sólida, heterogénea, de contornos imprecisos, infiltrativa e que causava deslocamento da veia jugular interna. O Rx do tórax e as análises estavam normais, nomeadamente o hemograma, PCR, VS, provas hepáticas, renais, proteinograma, LDH e VIH. Enquanto aguardava o resultado da citologia aspirativa do gânglio e a realização da prova de Mantoux foi pedida uma TAC cervical, dado os gânglios apresentarem características suspeitas na ecografia do pescoço e para melhor caracterização dos tecidos adjacentes. Regressa à consulta em dezembro com o resultado dos restantes exames, sendo que a TAC cervical confirmava uma lesão ovalar sólida, expansiva/proliferativa, mal delimitada, na região cervical inferior, à direita, $\operatorname{com} 4,5 \mathrm{~cm}$ x 2,5cm e com moldagem da veia jugular. A citologia aspirativa do gânglio mostrou uma alteração granulomatosa e a prova de Mantoux foi positiva. Foi estabelecido o diagnóstico de tuberculose ganglionar, tendo sido referenciada para o Centro de Doenças Pneumológicas, onde cumpriu nove meses de tuberculostáticos com remissão do quadro.

Ao longo dos anos, a utente manteve seguimento nas nossas consultas, sem intercorrências relevantes até que, seis anos depois, em janeiro de 2014, recorre à consulta por ter palpado uma tumefação na região supraclavicular direita. Não apresentava febre, suores, perda de peso, cansaço, tosse ou outra sintomatologia toraco-abdominal. Tinha uma mamografia recente que não tinha alterações significativas. À observação apresentava adenomegalias cervicais e supraclaviculares à direita de consistência dura, regulares, $c 0 m 1 \mathrm{~cm} \mathrm{x} 1 \mathrm{~cm}$, imóveis e indolores. Não apresentava adenomegalias noutras cadeias ganglionares, a observação do tórax era normal e o abdómen não revelou massas ou hepato-esplenomegalia. Foi, então, pedido Rx do tórax, ecografia abdominal, análises com hemograma, PCR, VS, provas hepáticas, renais, $\mathrm{LDH}, \mathrm{VIH}$, proteinograma e a citologia aspirativa do gânglio.

Foi dada indicação médica para realização célere dos exames e contacto imediato com a equipa médica para a apresentação dos resultados. A utente volta em março com o resultado dos exames e refere agora não palpar qualquer tumefação. À observação apresentava apenas um pequeno gânglio supraclavicular direito, de difícil palpação pela sua dimensão infracentimétrica, 
com remissão das restantes adenomegalias pré-identificadas.

A ecografia abdominal, as análises e o Rx do tórax não revelaram qualquer alteração. A citologia aspirativa mostrava linfócitos em vários estadios de maturação com grande sobreposição de células, dificultando a interpretação, sugerindo-se a excisão do gânglio para exame histológico. Dada a regressão das adenomegalias ao exame objetivo, pediu-se TAC cervical para verificar a sua existência, localização e dimensões, o que poderia condicionar a realização de biópsia excisional. Após duas semanas regressa com o resultado da TAC que relatava a presença de gânglios cervicais bilaterais e supraclaviculares, sem critérios de suspeição, tanto pelo número como pelas dimensões. Dada a redução das dimensões dos gânglios palpáveis ao exame objetivo, associado ao resultado da TAC, que não demonstrou a presença de gânglios de características suspeitas, assumiu-se estar perante um caso de adenomegalias de caráter inflamatório ou reativo em resolução, tendo-se optado por uma atitude expectante e de vigilância, ficando protelada a excisão do gânglio e a investigação de outras hipóteses diagnósticas, nomeadamente neoplasia gastrointestinal ou doença linfoproliferativa.

A utente manteve seguimento na nossa consulta, sem queixas relevantes e sem adenomegalias palpáveis nas consultas subsequentes, até cerca de dois anos depois, em fevereiro de 2016, altura em que refere queixas de dor no cotovelo esquerdo. À observação apresentava dor à palpação da epitróclea e edema do antebraço e mão esquerda, sem novas adenomegalias identificáveis ou outas alterações. Foi colocada a hipótese de uma tendinite dado a utente ter realizado, ao longo de todo o dia anterior, movimentos repetidos do braço a tocar cavaquinho. Foi proposta crioterapia, anti-inflamatórios não-esteroides e repouso.

Um mês depois volta à consulta e refere novo agravamento do edema da mão, antebraço e agora braço esquerdo. Não apresentava qualquer outra sintomatologia acompanhante. Neste contexto realizou Rx e ecografia, sendo que os exames não revelaram qualquer alteração. À observação na consulta subsequente apresentava edema de todo o membro superior esquerdo e adenomegalias supraclaviculares esquerdas, de consistência dura, contornos regulares, com $2 \mathrm{~cm} \mathrm{x}$
$2 \mathrm{~cm}$, imóveis e indolores. Não apresentava outras adenomegalias nem hepato-esplenomegalia. Foram colocadas as hipóteses diagnósticas de doença linfoproliferativa, recidiva de tuberculose ganglionar ou metástase de neoplasia da mama, pulmão ou gastrointestinal. Foi pedida uma TAC toraco-abdomino-pélvica, análises com hemograma, PCR, VS, provas hepáticas, renais, LDH e proteinograma e foi pedida uma citologia aspirativa do gânglio. Tinha uma mamografia realizada há cerca de três meses que era normal.

Cerca de três semanas depois volta à consulta com o resultado das análises, que não tinham alterações, e com a TAC que mostrou na região supraclavicular esquerda uma formação globosa com $3,5 \mathrm{~cm}$ x $2,3 \mathrm{~cm}$ com características de adenomegalia e na região axilar esquerda duas adenomegalias de $3,7 \mathrm{~cm} \mathrm{x} 2,6 \mathrm{~cm}$ e $1,8 \mathrm{~cm}$ $\mathrm{x} 1,7 \mathrm{~cm}$, associado a moderada compressão da veia subclávia esquerda.

Em abril de 2016 traz o resultado da citologia aspirativa do gânglio que mostrou a presença de células neoplásicas, sugerindo-se a excisão do gânglio para caracterização histológica. A utente foi enviada à consulta de cirurgia geral para excisão do gânglio, tendo como resultado um linfoma não-Hodgkin folicular grau 3A. Realizou um mielograma, que era normal, e repetiu a TAC toraco-abdominal que mostrou um aumento das dimensões dos gânglios da base do pescoço à esquerda, agora com $7 \mathrm{~cm} \mathrm{x} \mathrm{4,7cm} \mathrm{o} \mathrm{de} \mathrm{maior} \mathrm{dimensão,} \mathrm{pe-}$ quenas adenopatias retroperitoneais e duas lesões focais no baço inespecíficas, mas que poderiam ter significado no contexto atual. Apresentava ainda trombose da veia subclávia esquerda, estando medicada com heparina de baixo peso molecular e manga elástica. Iniciou acompanhamento em consulta de hematologia no Instituto Português de Oncologia de Lisboa, onde realizou quimioterapia com boa resposta, estando atualmente em remissão (Figura 1).

Ao longo do período de tratamentos manteve simultaneamente um contacto regular, presencial e telefónico com a sua médica de família, evidenciado sempre uma atitude positiva face ao diagnóstico e aos tratamentos que realizou com boa tolerância, não demonstrando sintomatologia sugestiva de patologia depressiva. Neste período, a médica de família desempenhou um papel ativo no esclarecimento de dúvidas e na tranquilização face aos receios demonstrados, o 


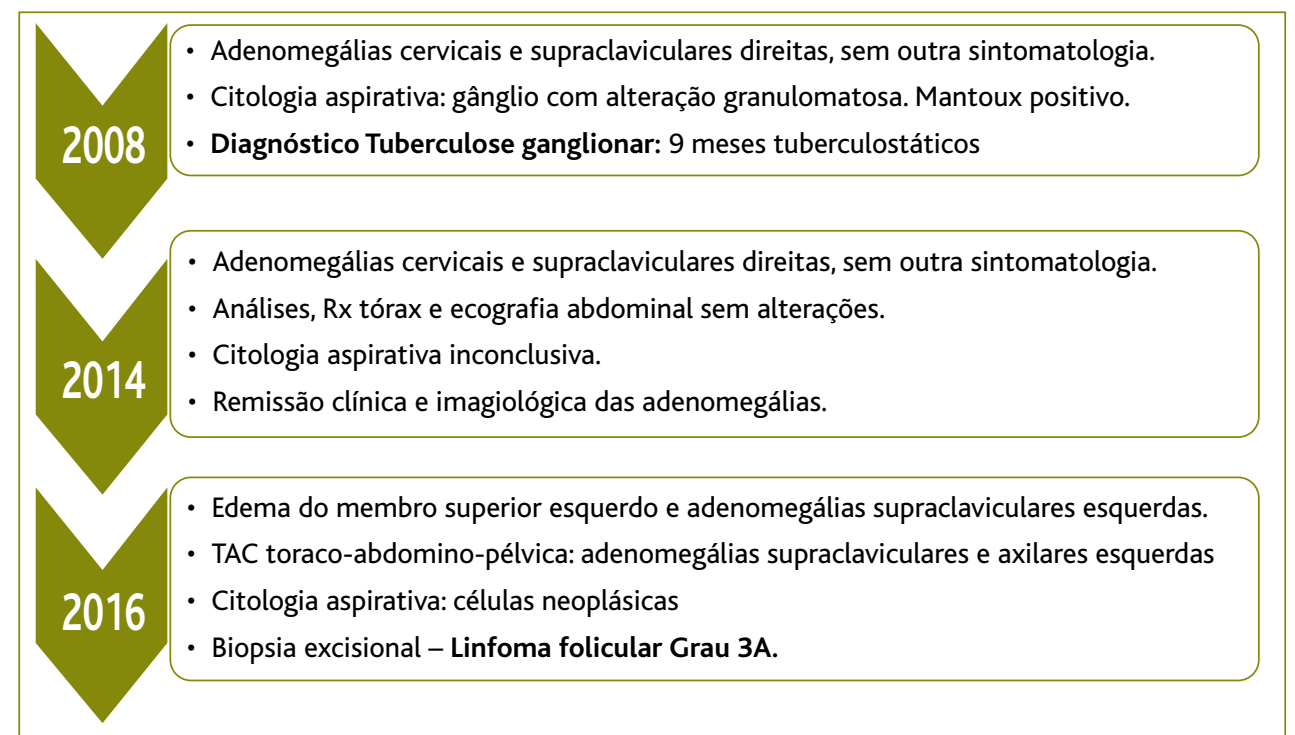

Figura 1. Cronograma da evolução clínica da doente.

que foi possível pela relação médica-doente já previamente construída. Foi ainda patente, ao longo destes contactos, a reorganização familiar perante a doença, com maior proximidade na relação com os filhos e o marido e consequente maior coesão familiar.

\section{COMENTÁRIO}

Este caso revela um quadro de adenomegalias de características suspeitas pela sua localização supraclavicular, consistência dura, mobilidade reduzida em relação aos planos adjacentes e pelas suas dimensões, sendo obrigatória a sua investigação imediata. Pelo contrário, na presença de adenomegalias que nos parecem benignas, tanto pela história clínica como pela observação, é possível manter a vigilância e aguardar a sua regressão por um período de duas a quatro semanas. ${ }^{1-2}$

$\mathrm{Na}$ presença de um doente com adenomegalias, a história clínica e o exame objetivo têm uma importância primordial na orientação do diagnóstico. Se estivermos perante um quadro de adenomegalias generalizadas, a anamnese deve ser dirigida no sentido de procurar sintomatologia e fatores de risco associados a infeções virais, infeções bacterianas, infeções fúngicas, doenças autoimunes, doenças linfoproliferativas ou o uso de fármacos (Quadro I). ${ }^{1-2}$ Já na presença de adenomegalias localizadas podemos dirigir a anamnese e o exame objetivo a alterações relacionadas com os órgãos que drenam para as respetivas cadeias ganglionares, não esquecendo que as etiologias referidas anteriormente também se podem manifestar de forma localizada. ${ }^{2-3}$

Os exames complementares de diagnóstico são dirigidos consoante as hipóteses diagnósticas resultantes da anamnese e exame objetivo. Na presença de adenomegalias generalizadas é mandatória a realização de

\section{QUADRO I. Exemplos de causas de adenomegalias generalizadas}

- Infeção viral (VIH, CMV, EBV, HSV, hepatite B)

- Infeção bacteriana (Mycobacterium, sífilis, brucelose, leptospirose, linfogranuloma venéreo)

- Infeção fúngica (Cryptococcus, histoplasma)

- Infeção parasitológica (toxoplasmose, leishmaniose)

- Doenças autoimunes

- Malignidade (leucemia, linfoma)

- Fármacos (alopurinol, atenolol, captopril, carbamazepina, fenitoína, cefalosporinas, penicilina, primidona, sulfonamidas) 


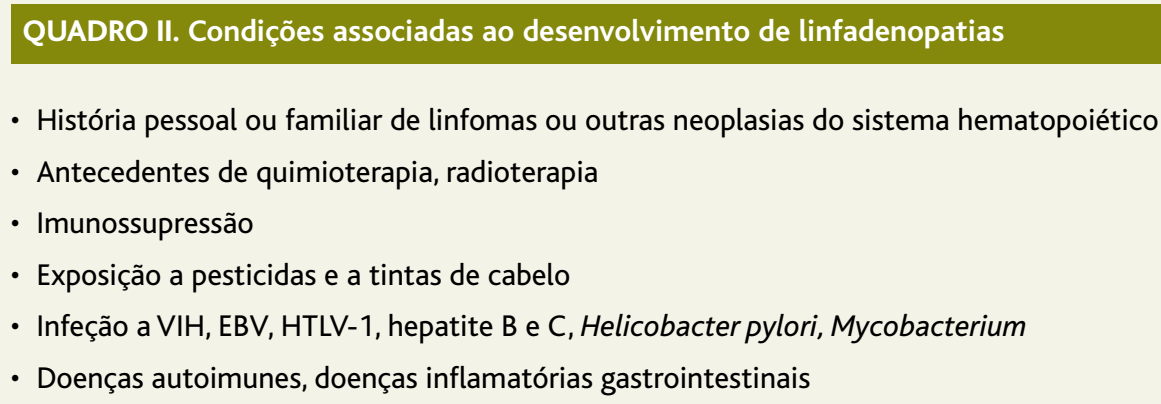

Legenda: HTLV-1 = vírus linfotrópico de células T humano tipo 1 (adaptado). ${ }^{1,6}$

uma avaliação analítica que inclua as etiologias referidas anteriormente, bem como o Rx do tórax. ${ }^{1-2}$ Nas adenomegalias localizadas, o exame de imagem é dirigido para os órgãos correspondentes à localização das adenomegalias. É de notar que, na presença de adenomegalias suspeitas, o exame histológico está recomendado para um diagnóstico definitivo. A biópsia excisional é o exame de eleição por permitir observar o gânglio na sua totalidade, diminuindo assim o número de falsos negativos. Além disso, permite manter a arquitetura do gânglio, o que é importante no diagnóstico dos linfomas. A biópsia com agulha ou a citologia aspirativa tornam-se menos úteis pelas questões referidas anteriormente; no entanto, por serem menos invasivos, tornam-se mais acessíveis podendo orientar o diagnóstico inicial. ${ }^{2-4}$

No caso da nossa utente, como referido anteriormente, esta apresentava adenomegalias suspeitas que mereceram uma investigação imediata. No entanto, a sua apresentação intermitente, com períodos em que os gânglios se encontravam de dimensões aumentadas e outros períodos em que regrediam espontaneamente e adquiriam dimensões e características normais ao longo de vários anos, dificultou e atrasou o diagnóstico.

O linfoma não-Hodgkin folicular é um linfoma indolente, que tem essa característica de poder manifestar-se com adenomegalias que aparecem e regridem espontaneamente ao longo de anos, podendo a sobrevivência sem tratamento chegar a anos. Este é o linfoma indolente mais comum, com uma incidência de 2,18 casos por 100.000 pessoas por ano, sendo igual em ambos os géneros. A idade média do diagnóstico é aos
65 anos. Existem diversos sistemas de classificação do prognóstico, nomeadamente baseado no exame histológico ou grau tumoral, sendo que este linfoma normalmente tem um bom prognóstico no grau 1, 2 e 3A, comportando-se de forma agressiva no grau $3 \mathrm{~B} .{ }^{3-5}$

Parece existir uma relação entre algumas condições e o desenvolvimento de linfoma, sendo que a nossa utente apresentava dois fatores, nomeadamente a história familiar de neoplasia do sistema hematopoiético no seu irmão gémeo e a história pessoal de infeção por Mycobacterium tuberculosis (Quadro II)., ${ }^{1,-6}$

Este caso torna-se particularmente interessante pela manifestação imprevisível das adenomegalias que, por um lado, se mostravam suspeitas e motivaram a sua investigação mas, por outro lado, regrediam espontaneamente, levando ao atraso de alguns anos no seu diagnóstico desde a sua primeira manifestação em 2014. Como referido anteriormente, a citologia aspirativa não é o exame de eleição para o diagnóstico dos linfomas, podendo levar a alguns resultados falsos negativos. No entanto, pela perceção adquirida ao longo da nossa prática clínica, este exame apresenta uma maior acessibilidade e rapidez de execução e, por esse motivo, perante um quadro que nos pareceu suspeito optou-se pela citologia aspirativa, no sentido de obter informação relevante para uma intervenção mais rápida. Esta situação retrata a nossa realidade enquanto médicos de família que, perante os recursos existentes, temos de optar muitas vezes não por aquilo que está recomendado como primeira linha, mas por aquilo que está disponível e que trará maior benefício para o utente no contexto em que se encontra. São estas questões e dúvidas com que o médico de família se depara fre- 
quentemente, em que tem de adequar os seus conhecimentos científicos às circunstâncias, realidade e contexto do doente, que o diferencia de todas as outras especialidades.

Apesar das dificuldades com que nos deparamos na nossa tão abrangente prática clínica, outra característica dos cuidados de saúde primários, que facilita a nossa atuação, é a acessibilidade e a continuidade de cuidados que permite ao médico de família vigiar, avaliar e acompanhar estas situações mais complexas, detetá-las e referenciá-las adequadamente, sendo este aspeto retratado neste caso, onde a vigilância ao longo dos anos permitiu detetar a recorrência do quadro, investigar e referenciar.

\section{REFERÊNCIAS BIBLIOGRÁFICAS}

1. Fauci AS, Braunwald E, Kasper DL, Hauser SL, Longo DL, Jameson JL, et al. Harrison's principles of internal medicine. 17th ed. New York: McGraw-Gill; 2008. ISBN 9780071466332

2. Fletcher RH. Evaluation of peripheral lymphadenopathy in adults [homepage]. UpToDate; 2013 Oct [cited 2016 Oct 7]. Available from: http://ultra-medica.net/Uptodate21.6/contents/UTD.htm?38/10/ 39080? source=see_link

3. Pangalis GA, Vassilakopoulos TP, Boussiotis VA, Fessas P. Clinical approach to lymphadenopathy. Semin Oncol. 1993;20(6):570-82.

4. Freedman AS, Aster JC. Clinical manifestations, pathologic features, diagnosis, and prognosis of follicular lymphoma [homepage]. UpToDate;
2013 Feb [cited 2016 Oct 7]. Available from: http://ultra-medica.net/ Uptodate21.6/contents/UTD.htm?24/46/25322

5. Freedman SA, Friedberg JW, Aster JC. Clinical presentation and diagnosis of non-Hodgkin lymphoma [homepage]. UpToDate; 2013 Oct [cited 2016 Oct 7]. Available from: http://ultra-medica.net/Uptodate21.6/contents/UTD.htm?26/61/27610?source=related_link

6. Wang SS, Slager SL, Brennan P, Holly EA, De Sanjose S, Bernstein L, et al. Family history of hematopoietic malignancies and risk of non-Hodgkin lymphoma (NHL): a pooled analysis of 10,211 cases and 11,905 controls from the International Lymphoma Epidemiology Consortium (InterLymph). Blood. 2007;109(8):3479-88.

7. Hainsworth JD, Greco FA. Overview of the classification and management of cancers of unknown primary site [homepage]. UpToDate; 2013 Oct [cited 2016 Oct 7]. Available from: http://ultra-medica.net/Uptodate21.6/contents/UTD.htm?14/26/14758?source=see_link

8. Emerick K. Differential diagnosis of a neck mass [homepage]. UpToDate; 2016 May [cited 2016 Oct 7]. Available from: https://www.uptodate.com/contents/differential-diagnosis-of-a-neck-mass

\section{CONFLITO DE INTERESSES}

As autoras declaram não ter quaisquer conflitos de interesse.

\section{ENDEREÇO PARA CORRESPONDÊNCIA}

Andreia Priscila Abreu Silva Araújo Caldeira

E-mail: apasa2@gmail.com

http://orcid.org/0000-0001-5681-6381

Recebido em 23-02-2017

Aceite para publicação em 02-03-2018 


\section{ABSTRACT}

\section{«INTERMITTENT» ADENOMEGALY: A CLINICAL CASE IN GENERAL PRACTICE}

Introduction: Adenomegaly is a frequent finding during physical examination, and it is important for the general practitioner to identify those that may be suspicious, and make a timely referral. This case shows an unpredictable manifestation of adenomegalies of suspicious characteristics, which appear and regress spontaneously over the years. With this case report we wish to draw attention to the need to always value suspicious adenomegalies, and also to elucidate on the diagnostic approach to these manifestations.

Case study: 69-year-old woman, with a history of lymph node tuberculosis in 2008, treated with tuberculostatic drugs for nine months. In 2014, following the identification of new cervical and supraclavicular adenomegalies of suspicious characteristics on the right, a new clinical investigation was performed, but the results were inconclusive given the spontaneous remission of the condition. Two years later, the patient returns showing supraclavicular adenomegalies on the left, which were further investigated by fine-needle aspiration cytology, showing the presence of neoplastic cells. The patient was referred to general surgery for excisional biopsy of the lymph node, which established the diagnosis of non-Hodgkin's follicular lymphoma. Chemotherapy was therefore initiated at the Portuguese Institute of Oncology (IPO), with good tolerance and response.

Comment: Follicular lymphoma is an indolent condition and may present as adenomegalies that appear and regress spontaneously during the course of several years, an unpredictable characteristic that hinders the diagnosis. However, the continuity of care characteristic of general practice facilitates the detection of the recurrence of the disease, and allows it timely referral.

Keywords: Lymphadenopathy; Non-Hodgkin's follicular lymphoma. 